\title{
REPULICATION
}

\section{Stress and Coping among College Students in the Dominican Republic}

\author{
Tykeysha M Thomas ${ }^{1}$, Felicia Schanche Hodge ${ }^{1}$, Suzanne Kotkin-Jaszi ${ }^{2}$, \\ and Aída Mencía-Ripley ${ }^{3}$ \\ ${ }^{1}$ University of California, Los Angeles \\ ${ }^{2}$ California State University, Fresno \\ ${ }^{3}$ Universidad Iberoamericana, Dominican Republic
}

Original Article: Thomas, T., Hodge, F., \& Kotkin-Jaszi, S. (2016). Stress and coping among college students in the Dominican Republic. Californian Journal of Health Promotion, 14(1), 57-62. URL: http://www.cjhp.org/volume14Issue1_2016/documents/57-

62_Thomas_CJHP2016_Issue1.pdf

\begin{abstract}
Background and Purpose: Stress is a common complaint among college students; however, stress is understudied specifically among Hispanics outside of the United States. A cross-sectional study investigating the stress-coping approaches utilized by Dominican college students living in the Dominican Republic (DR) is reported. Methods: Three-hundred three students, 27\% male and 73\% female, attending a private DR college completed a self-administered survey that inquired about their stress-coping approaches. Results: Older students in good academic standing were five times more likely to engage in exercise in response to stress $(\mathrm{p}=.006)$. Smoking cigarettes was significantly higher among White male students $(\mathrm{p}=.018)$. Students most often reported listening to music, using more than one stress-coping approach, or exercising in response to stress. Conclusion: This study identified stresscoping approaches utilized by college students attending a private university in the DR. Adaptive and maladaptive coping strategies were described. These findings differ from findings reported in studies conducted among other Hispanic college student populations that more often reported social support as a more commonly-used stress-coping approach.
\end{abstract}

(C) 2016 Californian Journal of Health Promotion. All rights reserved.

Keywords: Stress, Coping, Students, Dominican Republic

\section{Introduction}

Stress is a common complaint among young adults often attributed to the transition from adolescence to young adulthood (Mahmoud, Staten, Hall, \& Lennie, 2012; Erikson, 1994). Transitional stress for young adults is compounded by academic expectations and a lack of support systems (MacNeil, EspositoSmythers, Mehlenbeck, \& Weismoore, 2012; Mahmoud et al., 2012). When stress evolves into chronic depression, it can result in substance abuse and poorer decision-making, such as deciding to smoke cigarettes or engage in violent behaviors (Sternthal, Slopen, \& Williams, 2011; Thoits, 2010). Chronic stress is prolonged or repeated exposure to stressful events (APA, 2014). It is thought that these repeated exposures to stress eventually lead to negative mental and physical health outcomes (APA, 2014; Barksdale, Woods-Giscombe, \& Logan, 2012).

\section{Coping Theory}

Coping Theory identifies coping as both a style and a process (Folkman \& Lazarus, 1980). Coping style refers to emotional characteristics of coping, for example, defensive, offensive, aggressive, and passive behaviors (Folkman \& 
Lazarus, 1980). Adaptation and maladaptation are products of coping. Adaptation to stress is a positive outcome and implies that the stressful event was resolved in a satisfactory manner. Maladaptation is the negative outcome of coping that indicates the stressful event was unresolved. Adaptation to stress often depends on if the stressful event was addressed with positive coping behaviors, such as seeking out the support of family or friends (Misra \& Castillo, 2004). Maladaptive outcomes, such as anxiety, depression, or substance abuse, have been associated with maladaptive coping processes, for example, avoiding the stressor (Pagan et al., 2013; Chao, 2012; Misra \& Castillo, 2004; Folkman \& Lazarus, 1980).

\section{College Students in the Dominican Republic}

College students in the Dominican Republic (DR), like their peers in the United States (US), are in a stressful time of transition from adolescence to young adulthood (Mahmoud et al., 2012). Adjusting to adulthood and college life has been reported as frequent sources of stress for college students. Mahmoud et al. (2012) found that college students who reported maladaptive outcomes in response to new or more intense academic and adult expectations (i.e. changes in sleep habits, increased class workload, and having more responsibilities) more frequently reported having anxiety and depression.

Dominicans are one of the largest Hispanic groups; they are the $5^{\text {th }}$ largest Hispanic population in the US and the $12^{\text {th }}$ largest Hispanic group internationally (Brown \& Patton, 2012; Countries of the World, 2012). Dominicans are strongly represented at college level as compared to other Hispanic groups in the US (Brown \& Patton, 2012). However, there are no known studies of their stress-coping approaches. A small number of studies have reported the use of family and community support systems by other Hispanic cultures during stressful events (Pagan et al., 2013; Calzada et al., 2012). Pagan et al. (2013) reported that Puerto Rican female college students were more likely than Puerto Rican male college students to use social support as a stress-coping strategy, and college students aged less than 25 years used social support more often than older college students. Mahmoud et al. (2012) reported that female students reported higher stress than male students, and students who described having social supports were less likely to report being stressed.

This study is a secondary analysis of data from a study on risk behavior and college students conducted by Mencía-Ripley and Vargas in 2011 and in this subsequent analysis we explored the stress-coping approaches utilized by Dominican college students attending a private university in the DR. The paucity of studies on Dominican college students and stress makes this study timely and relevant to those interested in understanding the stress-coping approaches utilized by this population.

\section{Methods}

\section{Study Design}

A cross-sectional study was conducted during the 2011 academic year. Participants were recruited via convenience sampling in their classrooms. The classrooms were visited by research assistants and students who met eligibility criteria and gave written consent completed the questionnaire. A full description of the methods section is available in MencíaRipley and Vargas (2014).

\section{Participants}

The original study included three hundred three students attending a private university in the DR to participate in a study that examined sociodemographic characteristics, substance use, mental health, and stress-coping approaches. Study inclusion criteria included self-identified men and women, aged 17 years and older, currently enrolled in the Spanish language academic programs offered at the university. All recruitment was coordinated by researchers and research assistants in the Dominican Republic. For the purposes of our secondary analysis, socio-demographics (e.g. age, gender, academic standing) and stress-coping approaches data were used for statistical analyses. 


\section{Procedures \\ Eligible students provided their informed consent and completed a 20-minute self- administered questionnaire. The Dominican research team assisted in disseminating the survey and ensuring completion. Participants returned completed surveys to the research staff in the DR. Surveys were then processed and data entered by the Dominican research team.}

Institutional Review Board approvals were obtained from California State University, Fresno and the private DR university. Study staff provided participants with information on the study in Spanish and explained the consenting process. Participating students read and signed the consent form, were provided a verbal and written overview of the project, told of their voluntary participation, and were assured that participation would not affect course grades, education or other university services. No incentives or payment were offered to the students for their participation in the study.

\section{Measures}

Demographic characteristics and health related survey questions were adapted from questions contained in the 2008 Behavioral Risk Factor Surveillance System (BRFSS) instrument (CDC, 2008).

The 2008 BRFSS questionnaire has demonstrated reliability and validity (CDC, 2013; Mokdad, 2009; Nelson et al., 2001). The version of the BRFSS that was used for this study was a Spanish language version developed by Palacio and colleagues (2008), which had been used in Colombia prior to use with Dominican participants (Palacio, Pérez, Alcalá, Lubo Gálvez \& Consuegra, 2008).

The independent variables were gender, age, ethnicity, and perceived academic standing and the dependent variables were the participants' stress-coping approaches.

Coping Responses. Categorical data was collected from participating students using questions created by the research team and adapted from the 2008 BRFSS questionnaire. Participants were asked to select one answer in response to the question: "When you are anxious or stressed, what do you usually do?" Answers included: "Exercise", "Listen to music", "Talk to my friends", "Talk to my family members", "I don't do anything special to relieve my stress", "Drink alcohol", "Smoke cigarettes", "Use illicit drugs" [marijuana, cocaine], "More than one of the listed activities". These answers were recoded into dichotomous variables, for which $1=$ the participant selected that answer (e.g., I smoke cigarettes to relieve my stress), and $0=$ the participant did not select that answer (e.g., the participant did not check off the "smoke cigarettes answer.”)

\section{Analyses}

Data analyses were performed using SPSS, version 23 (SPSS Inc., Chicago, IL). Statistical significance was set at $\mathrm{p}<0.05,2$-tailed. Frequencies were performed on demographic variables and the outcome variables of interest: stress-coping approaches. Logistic regressions were run to determine the relative influence of demographic variables (gender, age, ethnicity, and perceived academic standing) on each stress-coping approach. Categorical variables (ethnicity and stress-coping approaches) were recoded into dummy dichotomous variables. The reference group for ethnicity was "Mestizo", which was the largest ethnic group in the DR comprising $73 \%$ of the population (Central Intelligence Agency, 2014). Mestizos are a mixture of Black, White, and Indigenous/Taino ethnicities.

\section{Results}

Of the three-hundred three (303) Dominican college students who participated in the study, $82(27.1 \%)$ were male and $221(72.9 \%)$ female (see Table 1). A significant proportion of students (84.5\%) were aged 17-19 years. A majority of students $(53.8 \%)$ reported being Mestizo 35.3\% were White, $4.6 \%$ were Black, and $4.3 \%$ reported "other". Forty-nine percent reported that they were in good academic standing and 48.8 percent were in average standing. 
Table 1.

Participant Demographic Characteristics

\begin{tabular}{|c|c|c|c|}
\hline Variables & Categories & $\mathrm{n}$ & $\%$ \\
\hline \multirow[t]{3}{*}{ Age } & $17-19$ & 256 & 84.5 \\
\hline & $20-23$ & 39 & 12.9 \\
\hline & Other & 8 & 2.6 \\
\hline \multicolumn{2}{|l|}{ Total } & 303 & \\
\hline \multirow[t]{2}{*}{ Gender } & Male & 82 & 27.1 \\
\hline & Female & 221 & 72.9 \\
\hline \multicolumn{2}{|l|}{ Total } & 303 & \\
\hline \multirow[t]{4}{*}{ Ethnicity } & Mestizo & 163 & 53.8 \\
\hline & Black & 14 & 4.6 \\
\hline & White & 107 & 35.3 \\
\hline & Other & 13 & 4.3 \\
\hline \multicolumn{2}{|l|}{ Total } & 297 & \\
\hline \multirow{5}{*}{$\begin{array}{l}\text { Perceived } \\
\text { Academic } \\
\text { Standing } \\
\end{array}$} & Good & 147 & 48.5 \\
\hline & & & \\
\hline & & & \\
\hline & Average & 148 & 48.8 \\
\hline & Poor & 4 & 1.3 \\
\hline \multicolumn{2}{|c|}{ Total } & 299 & \\
\hline \multicolumn{4}{|c|}{ Stress-Coping Approaches } \\
\hline \multicolumn{2}{|c|}{ Listen to Music } & 303 & 60.1 \\
\hline \multicolumn{2}{|c|}{ More than 1 Thing Listed } & 303 & 23.4 \\
\hline \multicolumn{2}{|c|}{ Smoke Cigarettes } & 303 & 3.6 \\
\hline \multicolumn{2}{|c|}{ Exercise } & 303 & 3.3 \\
\hline \multicolumn{2}{|c|}{ Use Illicit Drugs } & 303 & 0.3 \\
\hline \multicolumn{2}{|c|}{ Talk to Friends or Family } & 303 & 0.0 \\
\hline \multicolumn{2}{|c|}{ Drink Alcohol } & 303 & 0.0 \\
\hline
\end{tabular}

\section{Stress-Coping Approaches}

Logistic regression results for stress-coping approaches are reported in Table 2. Listening to music $(60.1 \%)$ in response to stress was reported most frequently, followed by using more than one stress-coping approach listed (e.g. exercise, drinking alcohol, talking to friends or family) (23.4\%), smoking cigarettes (3.6\%), and exercise $(3.3 \%)$. Talking to friends or family $(\mathrm{n}=0)$, drinking alcohol $(\mathrm{n}=0)$, and using illicit drugs $(n=1)$ were the least-reported as stresscoping approaches and were therefore excluded from regression models.

The logistic regression model for exercise was statistically significant $(\mathrm{p}=.006)$ indicating that older DR college students who perceived themselves in good academic standing were up to five times more likely to engage in exercise in response to stress. The logistic regression model for smoking cigarettes was significant as well $(\mathrm{p}=.018)$. Participants who identified as White were 4.3 times more likely to smoke cigarettes than Mestizo participants, and males five times more likely than females to smoke cigarettes in response to stress. Listening to music and using more than one stress-coping approach could not be significantly predicted by the demographic variables used in the model.

Table 2.

Logistic Regression of Stress-Coping Approaches on Demographic Variables

\begin{tabular}{|c|c|c|c|c|c|c|c|c|}
\hline & \multicolumn{2}{|c|}{ Exercise } & \multicolumn{2}{|c|}{ Music } & \multicolumn{2}{|c|}{ Smoke } & \multicolumn{2}{|c|}{$\begin{array}{l}\text { More than } \\
1 \text { Coping } \\
\text { Approach }\end{array}$} \\
\hline & $\beta$ & OR & $\beta$ & OR & $\beta$ & OR & $\beta$ & OR \\
\hline Gender & 2.22 & 9.218 & .11 & 1.119 & $\begin{array}{c}- \\
1.56^{*}\end{array}$ & .210 &. & .779 \\
\hline Age & $.60^{*}$ & 1.822 & $\begin{array}{c}- \\
.14\end{array}$ & .870 & .02 & 1.024 & -.05 & .955 \\
\hline Ethnicity & & & & & & & & \\
\hline $\begin{array}{l}\text { White } \\
\text { Black }\end{array}$ & $\begin{array}{c}.03 \\
-\end{array}$ & $\begin{array}{l}1.026 \\
.000 * *\end{array}$ & $\begin{array}{l}.24 \\
.44\end{array}$ & $\begin{array}{l}1.227 \\
1.551\end{array}$ & $\begin{array}{c}1.47^{*} \\
-\end{array}$ & $\begin{array}{l}4.332 \\
.000 * *\end{array}$ & $\begin{array}{l}-.55 \\
-.29\end{array}$ & $\begin{array}{l}.575 \\
.750\end{array}$ \\
\hline Other & 1.65 & 5.216 & .11 & 1.117 & - & $.000 * *$ & -.29 & .750 \\
\hline $\begin{array}{l}\text { Perceived } \\
\text { Academic } \\
\text { Standing }\end{array}$ & $1.61 *$ & 4.979 & .04 & 1.039 & .58 & 1.783 & -.08 & .926 \\
\hline $\begin{array}{l}\text { Reference } \\
\text { response t } \\
\text { *significa }^{\text {s }}\end{array}$ & $\begin{array}{l}\text { oup fo } \\
\text { ress" } \\
\text { set at }\end{array}$ & $\begin{array}{l}\text { egressic } \\
.05\end{array}$ & & & & & & \\
\hline
\end{tabular}

\section{Discussion}

Examining types of stress-coping approaches among DR students informs interventions particularly those projects that target DR students can potentially aid in developing interventions for other minority students enrolled in educational institutions. The types of adaptive coping approaches reported by DR students included exercise and listening to music. These coping mechanisms were identified largely by female students. Maladaptive coping strategies identified were substance abuse activities and smoking cigarettes. Cigarette smoking was found to be significantly reported by White male students. Smoking cigarettes and substance abuse have substantial negative health implications. This finding identified an opportunity to develop programs aimed at educating students on smoking cessation and substance abuse, as well 
providing interventions to replace smoking and/or substance abuse with adaptive coping approaches without the negative health implications.

Although our results are not generalizable to all Hispanic students or Dominican college students, our study provides insight on alternative stress-coping approaches, such as using exercise and music to cope with stress, that differ from stress-coping approaches (e.g. support of family or friends, consultations with religious authorities, memberships in sororities and fraternities, and academic mentorships) previously reported about Hispanic college students (Reyes-Rodriguez, Rivera-Medina, Camara-Fuentes, Suarez-Torres, \& Bernal, 2013; Calzada et al., 2012; Pagan et al., 2013). Our study reports new findings that are unique compared to other Hispanic groups thus warrants further investigation of stress-coping approaches used among the various Hispanic cultures.

\section{Limitation}

This study was conducted in the DR at a private university therefore the findings may not represent students enrolled at other universities. Students were not surveyed on their varying levels of stress and sources of stress. Additionally, stress-coping approaches were limited to categories listed in the survey and may not be representative of stress-coping approaches in which DR college students most often engage. Future studies may identify levels of stress experienced, specific stressors, and stress-coping approaches more specific to DR college students.

\section{Conclusion}

The Dominican college student sample utilized in this secondary analysis was found to deal with stress independently. This finding is different from stress-coping strategy findings from studies conducted in other Hispanic college student populations that identified turning to social supports, such as family, friends, and religion. The difference in stress-coping strategies may be attributed to confounding factors such as social influences and life stage. Dominican students at private universities, such as the university where the data was collected for our analysis, are more often students from wealthier families and may have the financial means to live away from home while attending college thus their stresscoping strategy influences may be more social from friends and roommates. Another confounding factor may be a reflection of participants' stage of psychosocial development. The median age of our sample was 18 years; this age group is transitioning into young adulthood and attempting to establish an independent identity. In addition to being influenced by social supports established at the university, these DR students' stress-coping strategies may be based on transitioning into young adulthood. Future studies that investigate influences on stress-coping strategies utilized may provide significant insights about the differences in stress-coping strategies utilized among Hispanic college students and may provide valuable information that will help shape interventions that more directly target underlying confounding factors that lead to maladaptive stress-coping strategies.

Providers and counselors should be aware of the possibility that DR students at this particular private DR university have a history of and may continue to engage in maladaptive approaches such as smoking in response to stress and the differing responses of DR student participants by age, gender, and race. Our findings may provide insight when designing programs that discourage maladaptive approaches, such as smoking, and promote adaptive coping approaches identified by the DR college students (i.e. listening to music and exercising). Participants in our study may benefit from an on-campus recreation center that offers exercise or other culturally relevant physical activities with meeting areas where students can meet with friends and/or listen to music.

\section{Acknowledgements}

We particularly thank Dr. Aida Mencia-Ripley who designed and conducted the original study and Dr. Miguel A. Perez who organized the project and led the study's initial design.. The DR university officers were instrumental in the study by allowing us to recruit and implement 
Thomas, T.M., Hodge, F.S., Kotkin-Jaszi, S., \& Mencia-Ripley, A. / Californian Journal of Health Promotion 2016, Volume 15, Issue $1,78-84$

the study on site. Lastly, we appreciate the participating students who gave of their time and graciously agreed to participate in the study.

\section{References}

Palacio, L. M. A., Pérez, M. A., Alcalá, G., Gálvez, A. L., \& Consuegra, A. (2008). Comportamientos de riesgo para la salud en estudiantes colombianos recién ingresados a una universidad privada en Barranquilla (Colombia). Salud Uninorte, 24(2), 235-247.

American Psychological Association. (2014). Understanding chronic stress. Retrieved December 21, 2014, from http://www.apa.org/helpcenter/understanding-chronic-stress.aspx

Barksale, D. J., Woods- Giscombe, C., \& Logan, J. G. (2012). Stress, cortisol, and nighttime blood pressure dipping in nonhypertensive Black American women. Biological Research for Nursing, 15(3), 330- 337.

Brown, A. \& Patton, E. (2012). Statistical portrait of Hispanics in the United States. Pew Research Center. Retrieved April 30, 2014 from http://www.pewhispanic.org/2014/04/29/statisticalportrait-of-hispanics-in-the-united-states-2012/\#population-by-race-and-ethnicity-2000-and-2012.

Calzada, E. J., Tamis-LeMonda, C. S., \& Yoshikawa, H. (2013). Familismo in Mexican and Dominican families from low-income, urban communities. Journal of Family Issues, 34(12), 1696-1724.

Centers for Disease Control and Prevention. (2013). BRFSS Data Quality, Validity and Reliability. National Center for Chronic Disease Prevention and Health Promotion, Division of Population Health. Retrieved August 25, 2015, from http://www.cdc/gov/brfss/publications/methodology/data.qvr.htm.

Centers for Disease Control and Prevention. (2008). Behavioral Risk Factor Surveillance System Survey Questionnaire. Atlanta, Georgia: U.S. Department of Health and Human Services, Centers for Disease Control and Prevention, 2008. Retrieved August 25, 2015, from http://www.cdc.gov/brfss/questionnaires/index.htm

Central Intelligence Agency. (2014, June 22). The World Factbook. Retrieved March 21, 2014, from https://www.cia.gov/library/publications/the-world-factbook/geos/dr.html.

Chao, R. C. L. (2012). Managing perceived stress among college students: The roles of social support and dysfunctional coping. Journal of College Counseling, 15(1), 5-21.

Countries of the world. (2012). World Atlas. Retrieved April 30, 2014 from http://www.worldatlas.com/aatlas/populations/ctypopls.htm.

Erikson, E. (1994). Identity and the life cycle. New York, NY: WW Norton \& Company.

Folkman, S., \& Lazarus, R. S. (1980). An analysis of coping in a middle-aged community sample. Journal of Health and Social Behavior, 21(3), 219-239.

MacNeil, L., Esposito-Smythers, C., Mehlenbeck, R., \& Weismoore, J. (2012). The effects of avoidance coping and coping self-efficacy on eating disorder attitudes and behaviors: A stress-diathesis model. Eating Behaviors, 13(4), 293-296.

Mahmoud, J. S. R., Staten, R., Hall, L. A., \& Lennie, T. A. (2012). The relationship among young adult college students' depression, anxiety, stress, demographics, life satisfaction, and coping styles. Issues in Mental Health Nursing, 33(3), 49-156.

Mencía-Ripley, A., \& Caminero, Y. V. (2014). Abuso de sustancias en estudiantes universitarios Dominicanos. Medicina Salud y Sociedad, 4(3), 330-342.

Misra, R., \& Castillo, L. G. (2004). Academic stress among college students: Comparison of American and international students. International Journal of Stress Management, 11(2), 132-148.

Mokdad, A. (2009). The Behavioral Risk Factors Surveillance System: Past, present and future. Annual Review of Public Health, 30, 43-54.

Nelson, D. E., Holtzman, D., Bolen, J., Stanwyck, C. A., \& Mack, K. A. (2001). Reliability and validity of measures from the Behavioral Risk Factor Surveillance System (BRFSS). International Journal of Public Health, 46, 1-42.

Pagan, I., Fabian, C., Rios, J. L., Betancourt, J., Cruz, S. Y., Gonzalez, A. M., \& Rivera-Soto, W. T. (2013). Social support and its association with sociodemographic characteristics, dietary patterns, 
and perceived academic stress among college students in Puerto Rico. Puerto Rico Health Sciences Journal, 32(3), 146 -153.

Reyes-Rodriguez, M. L., Rivera-Medina, C. L., Camara-Fuentes, L., Suarez-Torres, A., \& Bernal, G. (2013). Depression symptoms and stressful life events among college students in Puerto Rico. Journal of Affective Disorders, 145(3), 324-330.

Sternthal, M. J., Slopen, N., \& Williams, D. R. (2011). Racial disparities in health. Du Bois Review: Social Science Research on Race, 8(1), 95-113.

Thoits, P. A. (2010). Stress and health major findings and policy implications. Journal of Health and Social Behavior, 51(1 suppl), S41-S53.

$\underline{\text { Author Information }}$

*Felicia Hodge, DrPH

Professor, School of Nursing and Public Health, 700

Tiverton Avenue, \#5-940 Factor Building, Los Angeles, CA 90095-1702. Telephone: (310) 267-2255; Fax: (310) 206-

3241. E-mail: fhodge@ sonnet.ucla.edu

* corresponding author 